\title{
Research on mobile cloud service model based on WBS
}

\author{
Manli Zhu ${ }^{1, *}$, Suzhen Wang ${ }^{1}$, Lu Zhang ${ }^{2}$ and Yanpiao Zhang ${ }^{1}$ \\ ${ }^{1}$ Hebei University of Economics and Business, Shijiazhuang Hebei, 050061, China \\ ${ }^{2}$ Tianjin University, Tianjin 300072, China
}

Keywords: Mobile cloud service platform, Work breakdown structure, Rural leisure tourism industry.

\begin{abstract}
The construction of mobile cloud service platform is innovative complex project. This paper analyzed service innovation behavior based on the four-dimensional model of service innovation, and to study the implementation process of mobile cloud service platform for rural leisure tourism based on WBS method multi-dimensional description, to propose a rolling, flow-based work breakdown structure design idea. The research results show that by properly setting the WBS and monitoring points, it is possible to detect and prevent the deviation of the progress cost correlation in time and to ensure the quality of the platform. Research results can provide the basis for decision making by relevant industry managers.
\end{abstract}

\section{Introduction}

Rural leisure tourism originated in Europe and developed rapidly in the United States, Britain, France, Japan and other countries. The development of this highly complex industrial model relies on natural environment and ecological agriculture, with landscape, production and recreation as the core. It is an important industry to develop rural economy, increase rural employment and increase farmers' income.

For the study of rural leisure tourism industry, the foreign scholars mainly concentrate on the concepts, related theories, historical evolution of development, problems encountered, development direction and policy support system. And the domestic scholars mainly focus on theoretical research.

Bilderbeek, Hertog, Marklund and Miles put forward the four-dimensional model of service innovation in 1998. The model extracts and integrates the key factors applicable to service industry, and establishes the service innovation dimension, which is a universal innovation model and provides a framework and ideas for the study of service innovation model. It includes four dimensions: new service concept, new customer interface, new service delivery system and new technology. Different dimensions are interrelated and correspond to different types of behavior patterns. Domestic scholars have given a new understanding of the

\footnotetext{
*Corresponding author: xmimi@126.com
} 
four-dimensional model of service innovation and carried out extensive research.

Work Breakdown Structure (WBS) method began in the mid-1980s. The Technical Committee for Quality Management and Quality Assurance of ISO has written WBS into international standards, pointing out that "project systems should be decomposed into manageable activities in engineering projects". WBS is the starting point of project management. With deliverables as its core, WBS decomposes projects into smaller and manageable work packages and activities step by step, providing a structured view of the content to be delivered.WBS each level of work is a more detailed and comprehensive description of the work at the previous level. Some scholars focus on rapid construction and continuous optimization of WBS; some scholars focus on performance prediction and effectiveness research of work breakdown of complex product projects; some scholars study the application of WBS in a certain field.

Based on the four-dimensional model of service innovation proposed by Bilderbeek and other scholars, this paper explores the innovative development model of rural leisure tourism industry in mobile cloud computing environment. Based on WBS method, this paper studies the design and implementation of mobile cloud service platform for rural leisure tourism.

\section{The four dimensional model design for rural leisure tourism industry innovation}

Different types of rural leisure tourism have different connotations of construction, but the construction objectives are the same. We must innovate the concept of development around the six elements of "food, housing, transportation, tourism, entertainment, shopping". The four-dimensional model of rural leisure tourism industry is shown in Fig. 1.

Dimension 1 - New service concept: Based on mobile cloud computing technology, we build a cloud service platform for rural leisure tourism industry, which provide precise interaction and connection channels for demanders, providers and regulators, and further realize not only the e-commerce of leisure tourism products, but also establish supply-side product chain and demand-side product chain. On this basis, we conduct product supply and demand analysis, hot sales analysis and forecast analysis.

Dimension 2 - New Customer Interface: A large amount of industrial information data is accumulated on mobile cloud platform. Service providers, industry managers and leisure tourists can share data resources. Service providers obtain information about actual customers and potential customers of leisure tourism products through the platform. Industrial stakeholders are actually involved in product design and innovation of the service enterprises.

Dimension 3 - New Service Delivery System: E-commerce of leisure tourism products has changed the way and process of business transactions. High-quality service products based on new service concept, new service ideas, new service processes and new customer interface are delivered to consumers through new service delivery system. Service providers should organize, manage and coordinate all links.

Dimension 4 - the new generation technology choice: the innovative design adopts the mode of "cloud platform + Internet + mobile terminal". It provides a platform environment for the supply, demand and supervision of rural leisure tourism industry to fully dock and interact. The new technologies of mobile cloud computing and big data analysis are the platforms, tools, methods and means to improve service quality. 


\section{Construction of Rural Leisure Tourism Mobile Cloud Service Platform Based on Work Breakdown Structure}

The construction of rural leisure tourism mobile cloud service platform is a complex system engineering. From the perspective of management, there are many stakeholders, a wide audience, high application level of information products and high user experience requirements. Its products belong to abstract and complex virtual knowledge products and it is difficult to control. It is of great theoretical and practical value to study the construction model of rural leisure tourism mobile cloud service platform.

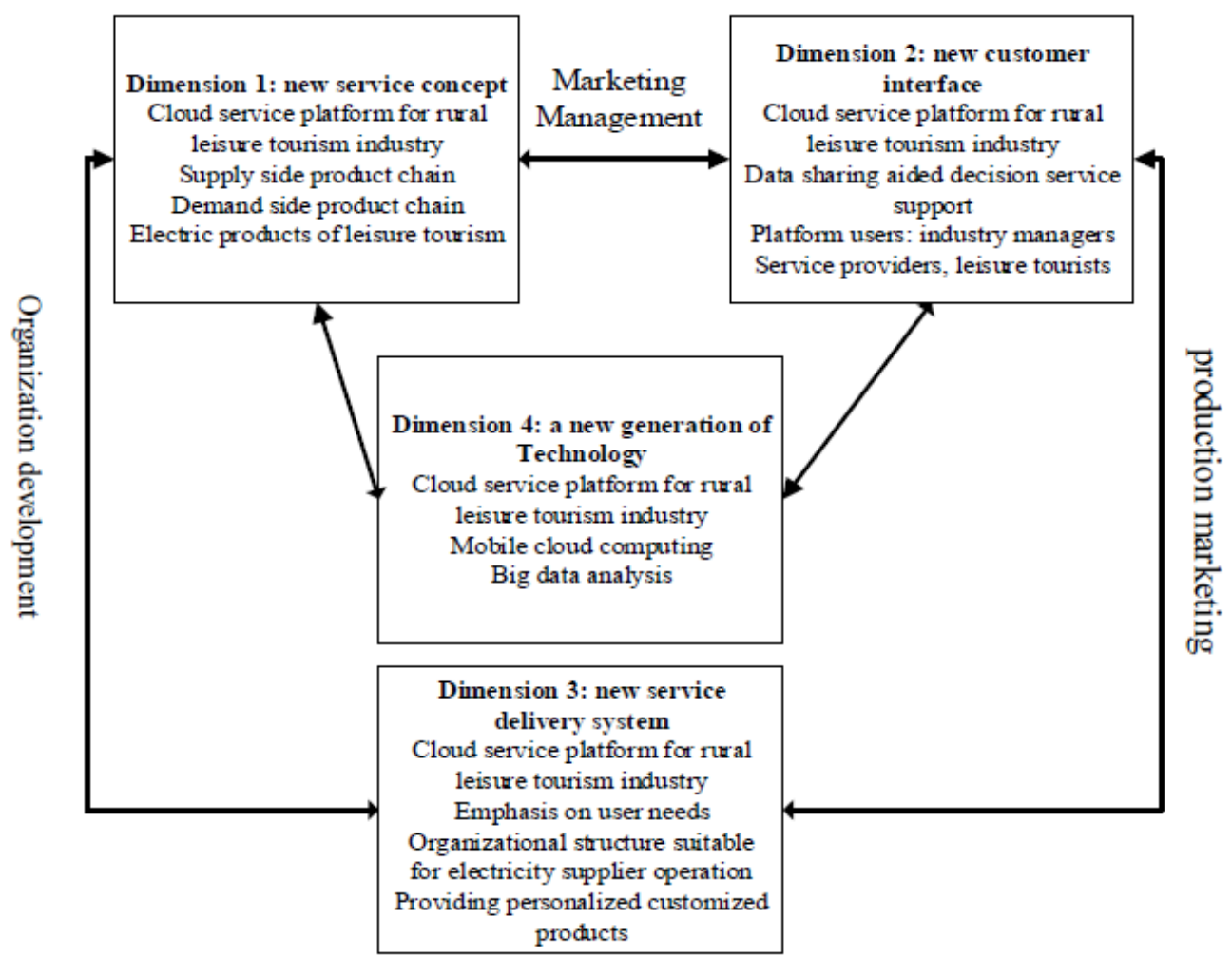

Fig. 1. Four dimensional model of rural leisure tourism industry.

The essence of the Work Breakdown Structure (WBS) is decomposition. According to the work objectives and results, the project structure is decomposed by layers, and the manageable and definable unit is divided to make the scope of work clear. Applying the WBS method to the construction of rural leisure tourism mobile cloud service platform can achieve reasonable control of schedule and cost, and achieve the goal of high quality and smooth completion.

\subsection{Work breakdown structure design strategy}

The rural leisure tourism industry mobile cloud service platform has a long construction time, wide coverage, and many stakeholders. The hard environment and soft resources of the platform construction, implementation methods and business processes are uncertain, and there is no experience and case to be referenced. The design also lacks a referenceable template, based on which the work breakdown structure design will take two strategies. 
(1) Hybrid work breakdown. Work breakdown does not take a single approach, according to demand, it can be broken down by function or by elements. It can also be broken down according to the process or professional content. According to the actual requirements, it can be expressed in the form of tree or table. Hybrid work breakdown comprehensively consider business, organization, resources, integration, execution and other elements.

(2) Rolling work breakdown. Continuous changes in information, resources and demand are often difficult to predict and analyze accurately and clearly. They can be solved step by step in the process of implementation, gradually explored and pushed forward, and gradually detail the work breakdown structure. Through the establishment of periodic work decomposition planning time points, all work and activities will be rolling carried out.

The construction of mobile cloud service platform in rural leisure tourism industry is an innovative project. The relationship between tasks is unstable. With the development of rural leisure tourism industry, new tasks will be discovered and new resources will appear. The concrete construction mode and the change of business process are also the influencing factors in the implementation process, and the correlation order of each sub-task is variable. Therefore, it is necessary to establish a complete top-level WBS, clarify the work breakdown structure of each stage in the process of construction, and adopt hybrid and rolling breakdown strategy.

\subsection{A sample based on work breakdown structure}

The construction of mobile cloud service platform for rural leisure tourism industry involves multi-fields and multi-objective connotation, and needs to collect information such as environmental conditions, resource allocation, stakeholder needs, and so on. And it needs to determine the specific way and business process of deliverables after in-depth analysis and communication. Rural leisure tourism industry mobile cloud service platform construction model is shown in Fig. 2.

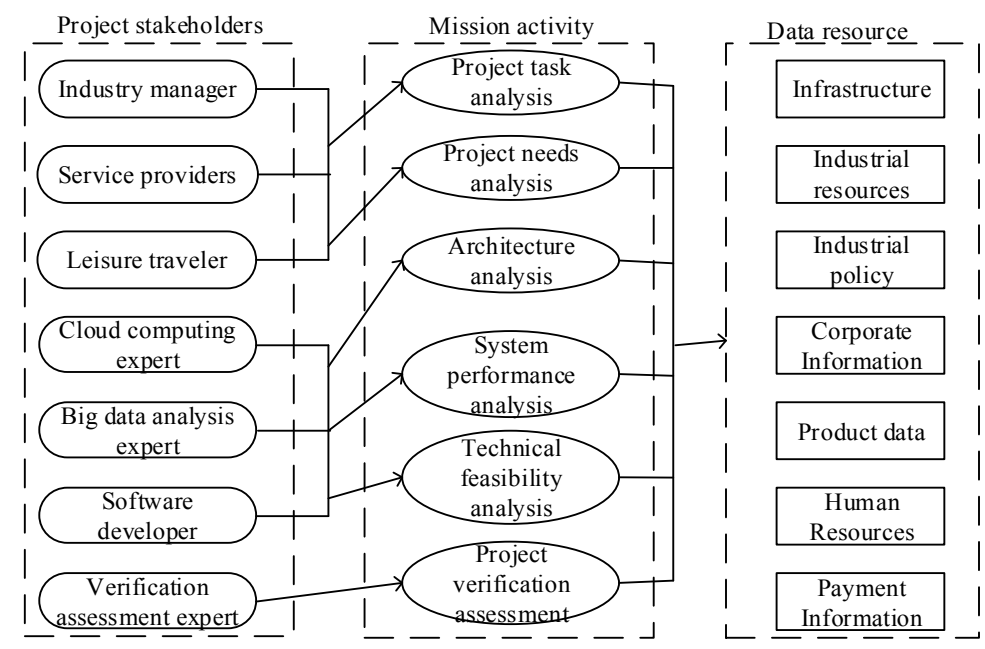

Fig. 2. Platform Construction Model.

\subsubsection{Work breakdown process design}

Based on the design principle of WBS, it can be effectively prevented the impact of uncertain 
factors caused by unclear subtasks by analysis effectively the task activity composition and interaction of Rural Leisure Tourism Mobile Cloud Service platform Construction, constructing the construction process of mobile cloud platform which adapts to the collaborative work of multi-domain experts and developing the rolling work breakdown planning.

Management content should be confirmed to ensure that each step in the traceability, monitoring. Part of the Data collection, project analysis, design and implementation of the three main departments of the work can be carried out concurrently. Each sub-task involves a considerable number of stakeholders. It is necessary to strictly design concurrent relationships between activities, reduce work costs and improve work efficiency. The construction of mobile cloud service platform is an innovative and complex project. The requirement analysis is very important, which directly affects the design and implementation of the following work. Considering comprehensively the professional fields and working steps involved in the platform construction, and then decomposing the more complex rural leisure tourism mobile cloud service platform construction needs analysis activities into a set of activities with a single objective and easy operation according to certain principles. Requirements argumentation can be subdivided into six activities: task analysis, requirement analysis, architecture analysis, technical requirements analysis, performance index analysis, and requirement verification evaluation. These six activities can be further broken down into a single, basic activity. The requirement analysis business process design is shown in Fig. 3.

\subsubsection{Stakeholder elements analysis for rural leisure tourism industry mobile cloud service platform}

There are many stakeholders in the mobile cloud service platform of rural leisure tourism industry, Straightening out their cooperation is conducive to construction and performance appraisal.

(1)Industrial managers. It includes local governments, independent management agencies and participating executive organizations. Its management strategy is collaborative strategy.

(2)Service providers. It includes designated state-owned enterprises, companies, cooperatives and self-employed operators. Its management strategy is participation strategy.

(3)Leisure tourists. It is mainly about the consumers of services. Its management strategy is to satisfy strategy.

(4)Platform manager. It includes platform construction department, operation Department and maintenance department. Its management strategy is participation strategy and guarantee strategy.

(5) Construction team. It includes the project leader, deputy leader, team leader and team member. Its management strategy is participation strategy.

\section{Conclusions}

(1) The supporting environment of mobile cloud computing technology is the prerequisite for the realization of new services in rural leisure tourism industry. Managers and practitioners of rural leisure tourism industry must always pay attention to the development and application of new technologies and grasp the initiative of service innovation.

(2) Mobile cloud computing enriches the customer interface of rural leisure tourism industry. Through platform interaction and large data analysis, leisure tourists can more accurately express and obtain demand. Industry managers and service providers can provide innovative services more accurately and drive service innovation through new demand. 
(3) The application of mobile cloud computing in rural leisure tourism industry has brought about systematic changes in organizational structure and service delivery. Scientific information flow system design can effectively improve the ability of service providers. Managers should attach importance to creating new mechanisms in order to improve service quality while reducing human capital.

(4) WBS can be used to realize the short-term, medium-term and long-term operational planning of rural leisure tourism industry development, and further realize the sustainable development of rural leisure tourism industry.

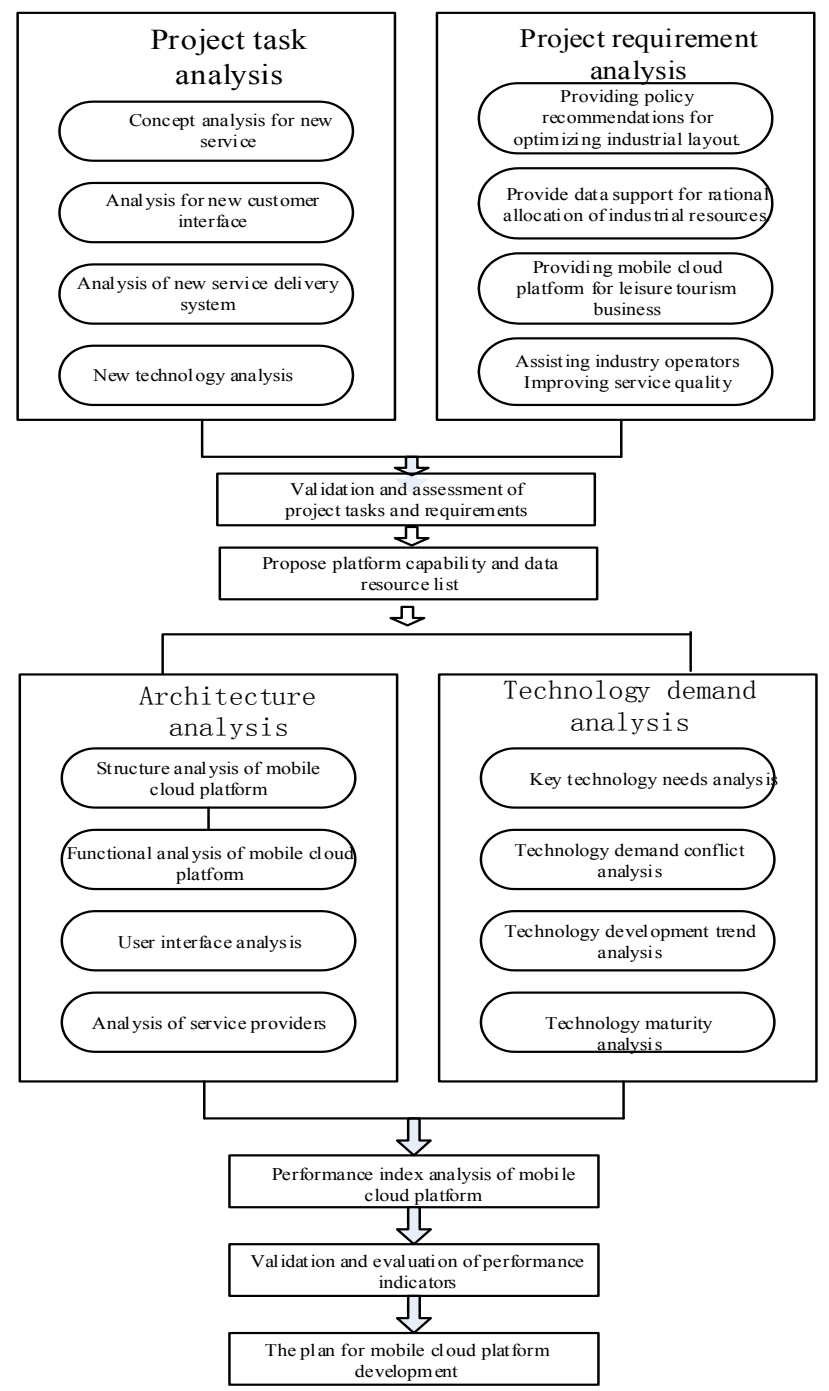

Fig. 3. Requirements analysis workflow.

(5) The use of WBS is conducive to coordinating various sub-tasks, clarifying the workflow, ensuring the success of platform construction and entering the healthy development and operation track, thus speeding up the integration of primary, secondary and tertiary industries.

(6) Using WBS to build a three-dimensional responsibility matrix model, we can combine 
the progress of the project, so as to be more realistic, selectively locate the body, surface and line, and manage the responsibility dynamically, carefully and concretely.

In the future, we need to do empirical research to explore the algorithm implementation based on big data optimization model and improved method. We should clarify the theory of rolling work decomposition stage division, discuss how to accurately divide the time points and principles of work decomposition, and further summarize the relationship and integration between work decomposition structure and business processes, organizational structure, data resources and other factors. This is the content of follow-up research.

This paper is partially supported by the Hebei Province Social Science Fund Project "Research on the Development of New Rural Service Industry Driven by Artificial Intelligence".

\section{References}

1. Project Management Association. Project Management Knowledge System Guide (PMBOK GUIDE). Electronic Industry Press. Beijing (2012).

2. Guoyun Li, Binglin Song. Research on innovative project decomposition and rolling planning. Project management technology14 (2), (2016)45-50.

3. Nan R, Mengyuan M, Bingjie H.: Research on WBS effectiveness of complex product project based on complex network. Journal of Jiangsu University of Science and Technology (NATURAL SCIENCE EDITION) 2015 (10), 496 - 500, 506(2015).

4. Mingjiang Z, Zhongyi Z.: The application of WBS (WBS) method in the management of hydrogeological survey project. Xinjiang nonferrous metals 2015 (3), 32-34, 38(2015).

5. Guoqing W, Zhiwen X.: Research on resource matching of emergency resources based on the W B S. R. B. Journal of Safety Science and Technology9 (10), (2017)59-63.

6. Yan X.:Risk identification of civil aircraft development project based on WBS-RBS method [J]. Value engineering, 2017 (12), 5 8-59(2017).

7. Chuanke W, Xin L, Shaobo H.:The design of general science engineering chief designer system based on WBS- take F project as an example. Project management technology 15 (2), 103-106(2017).

8. Wenjie G.: Research on the work breakdown technology based on the aeroengine verification machine development program. China High-Tech Enterprises2017 (1), 7 9(2017).

9. Jingfang L, Xiaoyan J, Pengzhu Z.: Work Breakdown Structure Oriented Project Reviewer Assignment Method. Journal of Chinese Computer Systems 2017(2), 319-322 (2017).

10. Long T, Lianhu C.:A Study on Effectiveness Evaluation of Seeker Simulation System Based on WBS Synthesis Method. Command Control \& Simulation2018(4),94-98(2018). 